\title{
Application of Deep Learning in Medical English Teaching Evaluation
}

\author{
Lu Han (D), Xiaoyu Yao, and Jing Yu \\ School of Humanities, Jiangxi University of Chinese Medicine, Nanchang 330004, Jiangxi, China \\ Correspondence should be addressed to Jing Yu; yujingtcmjx@163.com
}

Received 7 January 2022; Revised 21 January 2022; Accepted 25 January 2022; Published 8 March 2022

Academic Editor: Xin Ning

Copyright (c $2022 \mathrm{Lu} \mathrm{Han}$ et al. This is an open access article distributed under the Creative Commons Attribution License, which permits unrestricted use, distribution, and reproduction in any medium, provided the original work is properly cited.

\begin{abstract}
Although the fact that the reform of college English teaching has yielded mixed results, medical colleges have yet to achieve a breakthrough. Deep learning (DL) is a type of education that emphasizes higher-order thinking skills. It encompasses the state of learning, the learning process, and the learning outcomes. It emphasizes critical knowledge understanding, focuses on the integration of old and new knowledge, confronts real-world problems, and pays attention to reflection. This paper establishes the EMET (evaluation of medical English teaching) model based on the improved BPNN algorithm and analyzes the performance of this model using the improved BPNN algorithm. The simulation results show that the improved BPNN algorithm proposed in this paper has fast convergence speed, strong optimization ability, and generalization ability, effectively reducing the impact of human factors on index weight determination.
\end{abstract}

\section{Introduction}

The value and intrinsic function of English education as a component of China's higher education are self-evident. The medical English teaching model, for example, is influenced by it and tries to teach using a variety of material designs and modal resources, such as images, sounds, actions, languages, and so on, in order to improve teaching and learning effectiveness $[1,2]$. The humanistic spirit should be fully reflected in teaching in this case, and it should also be communicated to students via evaluation [3]. Textbooks compiled according to curriculum standards strive to meet the requirements of the curriculum in terms of teaching content, structure, arrangement, design of texts, exercises, and activities in order to cultivate students' learning abilities. The evaluation system must also ensure that this objective is met. As a result, evaluating the practical teaching quality at universities is an effective way to ensure that universities can significantly improve their teaching quality [4].

When one loves learning, one will naturally enter into deep thinking and DL (deep learning) [5]. Therefore, in order to open DL, it is necessary to design learning content that can stimulate students' learning enthusiasm, build a learning environment that supports students' various learning activities, and pay attention to the creation of an active learning culture [6,7]. EMET is an important means to check teachers' teaching work. EMET (evaluation of medical English teaching) can measure the level of teaching quality and the degree of reaching the goal so as to check out the gap [8]. Through EMET, it can not only check whether the teaching process follows the teaching rules, whether the teaching principles are implemented, but also make an effective diagnosis so as to find problems, sum up experiences, and teach plans. BPNN (BP neural network), as a new technology with a wide range of applications, provides a new way to solve nonlinear problems with its powerful characteristics of self-learning and self-organization.

Given the success of DL technology in other fields, applying the BPNN theory to EMET [9] will be a worthwhile endeavor. Teachers' enthusiasm for doing a good job in active teaching can be sparked by EMET, which allows teachers to compare themselves horizontally and gain motivation and vitality in the competition. The evaluation process must be objective, fair, and persuasive in order to truly stimulate the teaching quality of teachers. BPNN's 
self-organization, self-adaptability, and self-study habits were used to create this model.

\section{Related Work}

At present, college English teaching in medical colleges is being carried out in an orderly manner [10]. Literature [11] according to the present situation of English teaching in China, it is proposed that English teaching in universities, primary and secondary schools should form systematic planning and management in the aspects of the syllabus, textbook selection, and test evaluation so as to change the long-standing problems in English teaching in China, such as time-consuming and inefficient, improper selection of textbooks, disjointed connection of different stages, and so on. Literature [12] deeply reflects on the major problems in the field of college English teaching in the past 20 years and puts forward many problems worthy of deep thought and experience that can be used for reference. Literature $[13,14]$ analyzes the problems existing in English teaching and puts forward corresponding reform measures according to the objective reality and hardware and software conditions of English teaching in China. Literature [15] gives a detailed introduction and thorough analysis from the aspects of compilation principles, content arrangement, and usage of college English textbooks, which are of great significance to college English teaching. Literature [16] put forward the basic outline of research and teaching work and formulated the four-level grading standard, which made the evaluation index more operable. Literature [17] through a questionnaire survey or online evaluation, data is obtained, and then the scores of all evaluation objects are calculated by a computer system, and then the grades are determined according to the scores. Literature [18] constructs a remote EMET model and implements EMET based on support vector machines, which achieves good evaluation results. Literature [19] puts forward an EMET method based on an intelligent algorithm, which uses genetic algorithms to improve the evaluation teaching quality of BP neural network and has fast convergence speed and evaluation accuracy.

According to the literature [20], EMET is a complex problem in which many factors interact with one another, such as teaching conditions, curriculum difficulty, teachers' teaching, learning effects, and so on. The EMET system is considered in literature [4], and it is designed primarily from the most basic factors that can directly reflect teaching quality and have common characteristics. According to the literature [21], using DL theory to build an EMET model can not only overcome the inherent flaws of traditional evaluation methods but also produce EMET results quickly and accurately, providing scientific and reasonable decision-making data for higher education, teaching, and management. The evaluation of teachers' enthusiasm for work, proficiency in classroom teaching, whether they pay attention to ability training and teaching and educating people, and whether they pay attention to ability training and teaching and educating people, according to literature [22], is the most authoritative, and they should be the evaluators of teaching quality. Literature [23], which started the domestic multimodal discourse analysis theory research, introduced the multimodal discourse analysis theory from the perspective of social semiotics. Literature [24] research shows that the teaching tasks of English teachers in medical colleges are quite demanding and that the average weekly hours of $89.1 \%$ of teachers are between 16 and 22, making it difficult for them to pursue additional education and training and that there is almost no time for teaching research. Literature [25] according to the findings, English professors in medical schools pay more attention to the first and second development models.

\section{Research Method}

3.1. EMET System Construction. For English teaching in medical colleges, modular English teaching can improve the systematicness, integrity, and transition of English teaching. Module teaching has gradually attracted attention and application in basic English teaching. The cultivation of professional communicative competence is taken as the mainline, and the goal of introducing oral and written professional information and discussing it with colleagues at home and abroad in English should be achieved. So that modular teaching can play its role of self-contained and effective connection.

Medical English is a type of functional and applied English. Module teaching in this field is still in its early stages of research. Module teaching, as a new and interdisciplinary course in this field, necessitates students having a high level of comprehensive knowledge and strong language skills. Medical English articles have distinct and characteristic grammatical features, as well as a large number of long and difficult sentences. Students who are confronted with professional English for the first time will be befuddled and frustrated. Teachers are more likely to pay attention to which indicators are used for evaluation when using EMET indicators. Otherwise, the meaning of the teaching evaluation will be lost due to the arbitrary index selection. Students are the objects of evaluation in the learning evaluation system, and supervisors, teachers, other students, and students themselves are the evaluation subjects. Teaching and EMET supervision and evaluation, among other things, peer evaluation, student self-evaluation, supervision evaluation, and teacher evaluation are all indicators of a learning evaluation system. All of the indicators are interconnected and influence one another, resulting in an all-encompassing university EMET system (Figure 1).

The design of test questions should increase the application-oriented test questions with context, reduce the objective questions appropriately, and increase the subjective questions so as to truly test the students' ability of thinking, expression, and communication.

The final exam also takes the form of doing projects, completing tasks, performing, demonstrating, writing papers, etc. We try to fully examine students' comprehensive language use abilities. These advances make the evaluation more and more scientific. 


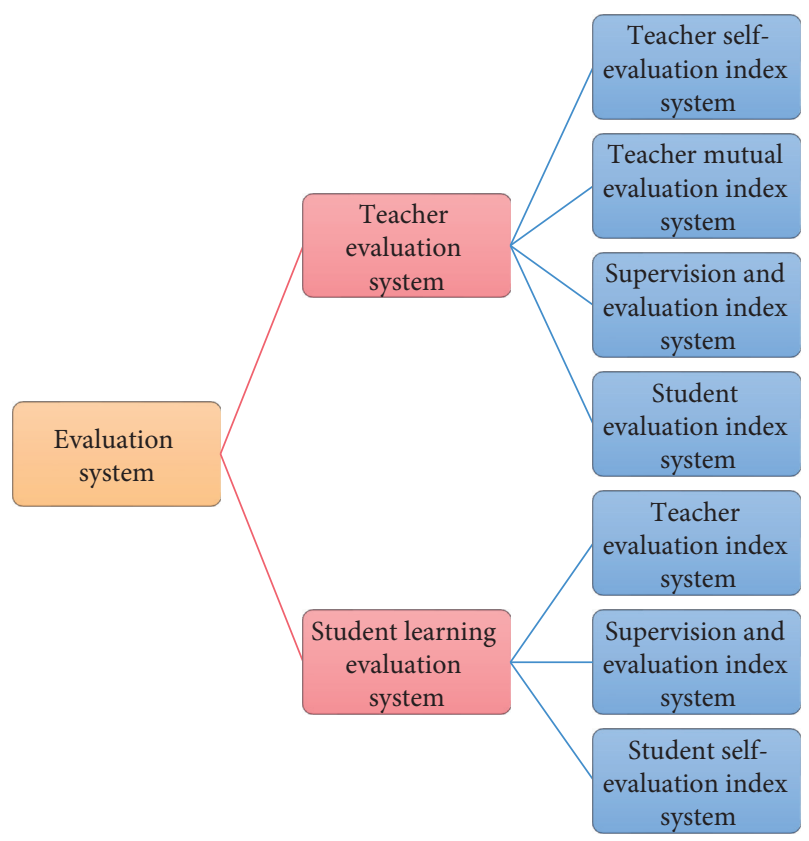

Figure 1: EMET system.

3.2. BPNN Model and Its Improvement. The structure of the BPNN is shown in Figure 2.

The standard BPNN algorithm is a gradient descent algorithm, which adopts the Widrow-Hoff learning rule, and the change direction of its weights and thresholds is the fastest descent direction according to the operation function, the negative direction of the gradient. An iteration period of the algorithm is

$$
w^{k+1}=w^{k}+\Delta w=w^{k}-\eta^{k} \frac{\partial e^{k}}{\partial w^{k}}
$$

where is the $k$ th weight or threshold vector; $\eta^{k}$ is the $k$ th LR (learning rate); and $\left(\partial e^{k} / \partial w^{k}\right)$ is the $k$ th error gradient.

The BPNN algorithm is a nonlinear optimization method based on the gradient descent method, which inevitably has a local minimum problem. Moreover, the solution space of practical problems is often an extremely complex multidimensional surface, and there are many local minima, which greatly increases the possibility of being trapped in the local minima. Generally, when the initial weights are randomly set in the BPNN algorithm, the training of the network is generally difficult to achieve the global optimum.

The flat area of the error surface will significantly increase training times, affecting convergence speed. However, multiple minima of the error surface will cause the training to fall into local minima, preventing it from convergent to a given error. The above two issues are BPNN's inherent flaws, which are rooted in the principle of weight adjustment based on the decline of error gradient, with each step of the solution leading to a local optimum. The LR decreasing method, local LR adaptation based on sign transformation, and LR automatic adjustment are all examples of improved algorithms [22]. The difficulty in selecting LR is the primary cause of the algorithm's slow convergence. At the start of training, determining the optimal LR can be difficult. The LR setting has a big impact on the algorithm.

If LR is too small, the convergence speed will be too slow; if LR is too large, it may converge too much, resulting in training shock. Therefore, the step size can be dynamically modified and the LR can be changed according to the training situation. It is amended as follows.

The initial output and error of the network are calculated as

$$
w_{j i}(n+1)=w_{j i}(n)+\eta(n) D(n) .
$$

Here, $D(n)=-\left(\partial E / \partial w_{j i}\right)=\delta_{j} x_{i}$ is the negative gradient of $n$ moment.

The change of $\eta$ will affect the change of weight, so choosing the appropriate rate can provide the system with a better learning method. The choice of speed should not cause oscillation, and the speed should be as large as possible. In this method, the momentum term is added to the adjustment quantity, and the adjustment quantity is required to be remembered every time. The weighted adjustment formula is

$$
\Delta \omega(t+1)=\eta \frac{\partial E}{\partial \omega}+\alpha \Delta \omega(t)
$$

Generally, $\alpha$ is about 0.9 , where $\alpha$ is the momentum coefficient.

If the LR value is too large, the network may be overcorrected, so it will not converge. Therefore, the choice of LR is very important, and its weight and threshold $\Delta X$ need to be updated, so the BPNN algorithm of selfadjusting LR can be described as

$$
\begin{gathered}
\Delta X=L_{r} \times \frac{\partial E}{\partial X} \\
\Delta X(k+1)=m c \times \Delta X(k)+L_{r} \times m c \times \frac{\partial E}{\partial X} .
\end{gathered}
$$

Here, LR is a variable, expressed as $L_{r}$ and the momentum is $m c$.

Type $s$ function is EF (excitation function) commonly used by the BPNN algorithm. However, the S-type function will lead to low learning efficiency. Therefore, improving the BPNN algorithm model can improve EF.

$$
f(x)=\left(\frac{0.5}{\lambda}\right) \sin (\lambda x)+\left(\frac{0.5}{\lambda}\right) \text {. }
$$

In this way, the degree of excitement between two connected neurons in the layer can be changed. When the period of function $f(x)$ changes, its amplitude can also change with the change of function period, thus changing the corresponding connection weights.

3.3. EMET Model Based on Improved BPNN Algorithm. From the main body of evaluation, there are currently two types of EMET for universities: the first is the continuous evaluation of undergraduate teaching levels in universities by governments at all levels or social intermediary organizations, and the second is the external evaluation. The other 


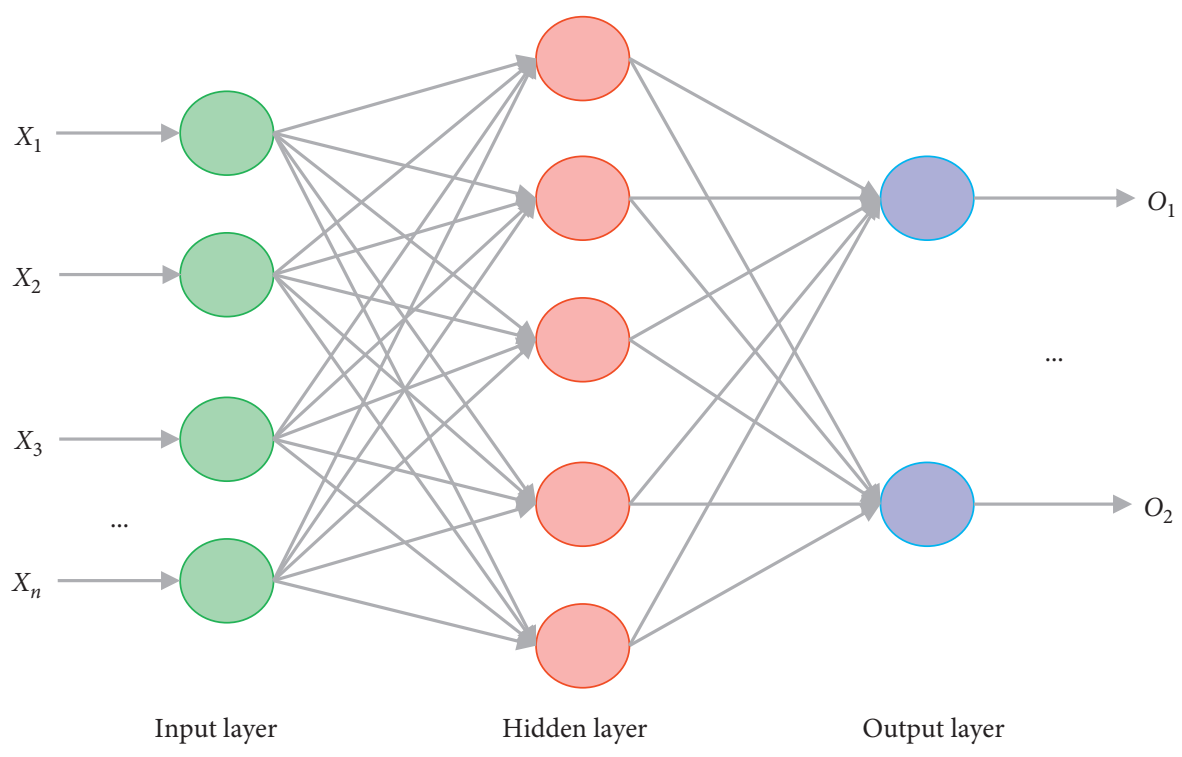

FIGURE 2: Structure of neural network.

is a quality standard system for a series of teaching links, such as the teaching plan and curriculum system, which are formulated by universities according to their own realities, and then the EMET comprehensive index system is established by scientific evaluation means to check the implementation of quality standards of each teaching link.

The following is the basic idea behind applying BPNN to a comprehensive evaluation of a teacher's teaching quality.

The training sample is the sample group selected by teacher evaluation when using BPNN to conduct EMET. The evaluation model is generalized after training and learning and can be used to assess the teaching quality of teachers in a variety of schools. Because neural networks obtain all of their parameters through training and learning, they are more objective and reasonable than other traditional EMET.

The specific steps of establishing the EMET neural network model are as follows:

Because there is only one evaluation result for the students' teaching, the OL (output layer) of the network is only set to one output node. The value range is $[0,1]$, which is common.

$$
\begin{aligned}
& m=\sqrt{n+l}+a, \\
& m=\log _{2} n, \\
& m=\sqrt{n l},
\end{aligned}
$$

where $m$ is the number of HL (hidden layer) nodes, $n$ is the number of IL (input layer) nodes, 1 is the number of OL nodes, and $a$ is a constant between 1 and 10 .

The activation function on the HL cell selects the tansig hyperbolic tangent function. The function form is

$$
f(x)=\frac{1}{1+e^{-x}}
$$

Based on the above analysis, the determined BPNN structure is shown in Figure 3.
Through experimental comparison, this paper sets the initial range of the network connection weights and thresholds as $[-1 / n, 1 / n]$.

Fundamentally speaking, to establish the EMET system under the guidance of the important thought of advancing with the times, the evaluation system to be established must advance with the times, be able to correctly reflect the actual situation of university EMET, and provide a direction and goal for schools and teachers to strive for. Therefore, comprehensive and objective evaluation from all aspects of teaching activities can make all aspects related to teaching development. Because of the complexity of teaching activities, it determines its multifactor, multilateral, and multilevel multidimensional structure. Therefore, it is necessary to use behavioral and operating methods to unify standards, strive to grasp the crux of the problem, and reflect the essence of things.

\section{Results Analysis and Discussion}

The mixed learning environment formed by the mutual integration of traditional classroom environment and digital learning environment is the reasonable integration and complementary advantages of objectivism and constructivism epistemology, aiming at changing the "transmission-acceptance" mode of traditional classroom and supporting students' effective transition from receptive shallow learning to DL.

This requires that in the design of network learning environment, not only to provide a variety of learning tools and learning resources but also pay attention to the design of incentive mechanism and the full play of teachers' role as the organization and management of learning so as to realize the benign transformation of students from passive "utilization" to active "coconstruction and sharing". When the learning environment becomes a space for students to enjoy, students will become masters of learning, and deep thinking and DL will happen quietly. 


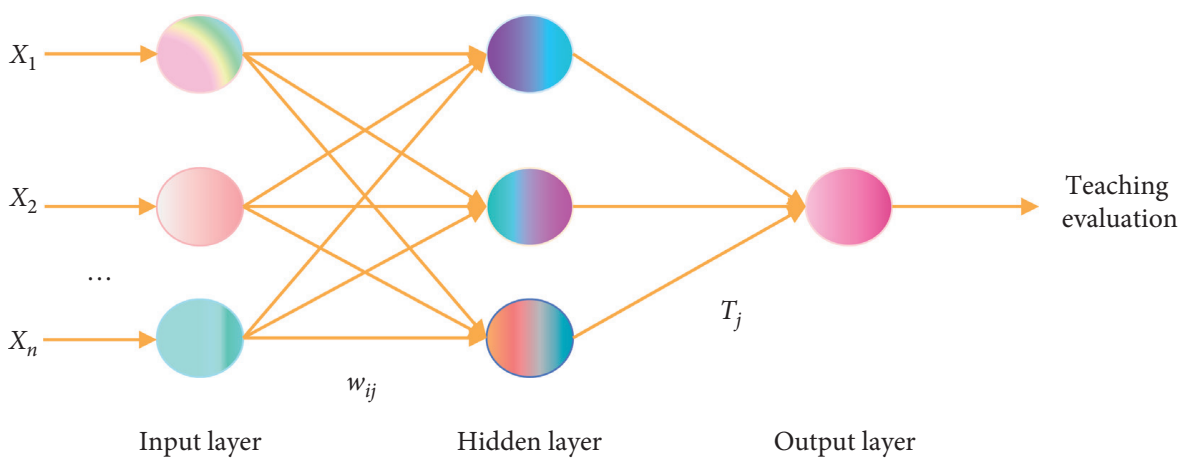

Figure 3: BPNN model diagram of the EMET system.

In the university EMET system, the method of collecting input data information adopts the method of students' online evaluation. Combined with the data of students' evaluation of a course in medical college, the sample shown in Figure 4 is obtained.

Setting up student files before the start of the course allows you to collect personal information related to the course learning through online questionnaires and organize all the useful information to guide students to DL. According to the progress of learning, teachers conduct online thematic discussions and organize students to communicate with common problems encountered in the learning process.

After the completion of the learning task, the sharing, discussion, evaluation, and feedback of learning results are arranged. Teachers and students collide with each other's criticism and anticriticism, negation, and affirmation, which can inspire new learning reflection and promote learners' deep thinking and deep processing of knowledge.

Therefore, the consideration of the EMET system is mainly designed from the most basic factors that can directly reflect the teaching quality and have common features. The curve of mean square error in the training process of the model is shown in Figure 5, and the EMET precision of the test group data is shown in Figure 6.

Figure 5 shows that the original BPNN converges after about 45 iterations while the improved BPNN only needs about 30 iterations, which indicates that the improved BPNN can effectively improve the convergence speed of the original BPNN and reduce the training time of the model.

The teaching of medical English will have little impact if medical universities continue to follow the same English syllabus as regular colleges and universities. A management strategy consists of a set of management mechanisms, methods, and learning evaluations. The management of traditional classroom work reporting activities demonstrates that teachers relinquish authority, return the classroom to students, encourage students to participate in learning interactions, create a positive and enthusiastic classroom environment, and evaluate the learning process performance.

In the network learning environment, the incentive mechanisms of various social software can be borrowed, such as reflecting students' participation in learning activities and their contribution to the network learning platform

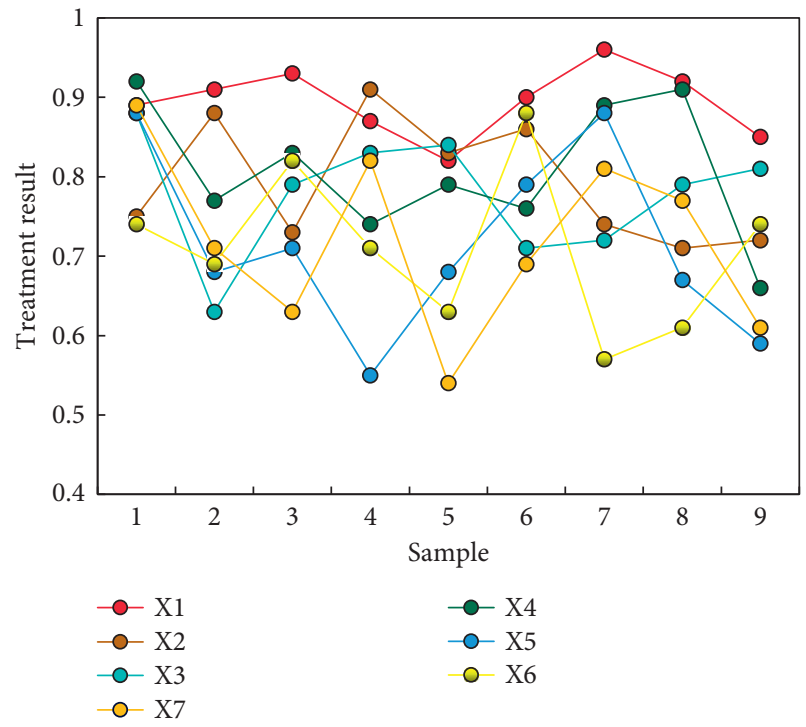

Figure 4: Initialized sample data.

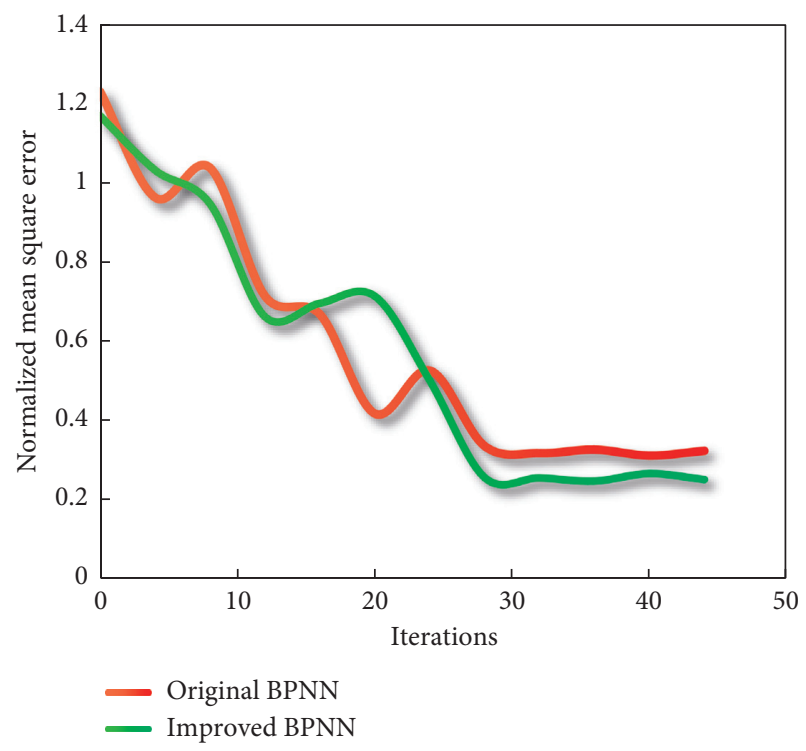

Figure 5: Mean square error curve of the model. 


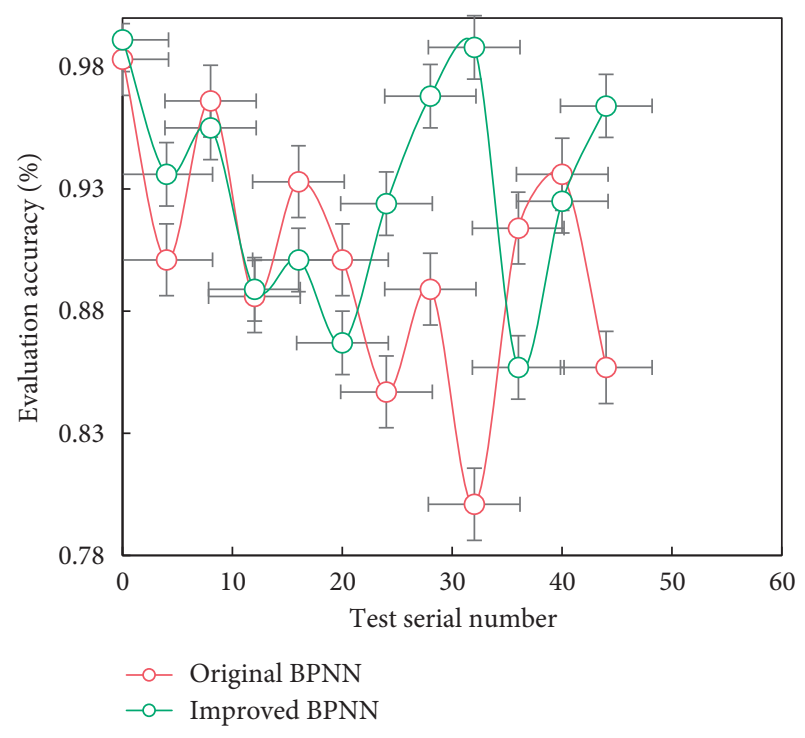

FIgURE 6: Evaluation accuracy curve of the model.

with parameters such as experience value and heat and bringing these data into the learning evaluation system.

Figure 6 shows that the accuracy of the original BPNN meridian for EMET is higher than $80 \%$, but the evaluation accuracy of the improved BPNN meridian is better than that of the original BPNN meridian, which indicates that the model has high approximation accuracy.

In the classroom teaching process, teachers teach vocabulary and grammar knowledge and give instructions for students to practice specific language skills. The form and time of practice are controlled by the teachers. In this mode, students have no initiative at all, and their learning needs cannot be met. According to cognitive theory, learners are not passive receivers in the process of language learning; they are cognitive subjects and active constructors of knowledge systems. However, at the present stage, due to the large capacity of college English classes and the long history of passive learning mode of students, learners' subjective initiative and autonomous learning spirit in classroom teaching are often neglected, which leads to the phenomenon of "time-consuming and inefficient" in medical college English teaching mode for a long time.

Eight people were selected from 20 samples that had been studied for evaluation, and the network evaluation results were obtained. In order to find out the actual evaluation results and compare them with each other, an anonymous questionnaire survey was used, and 20 experts from the class inspection supervision team of the college were asked to objectively and fairly score the factors and attributes of the evaluated personnel, and then the weighted average was converted into an accurate value between $(0,1)$, representing the actual evaluation results. A regression analysis was performed on them and got the regression analysis as shown in Figure 7.

In the ecological learning environment, learners not only make use of the environment in the form of consumers but also make their own contributions to the learning environment in the role of producers. In the process of

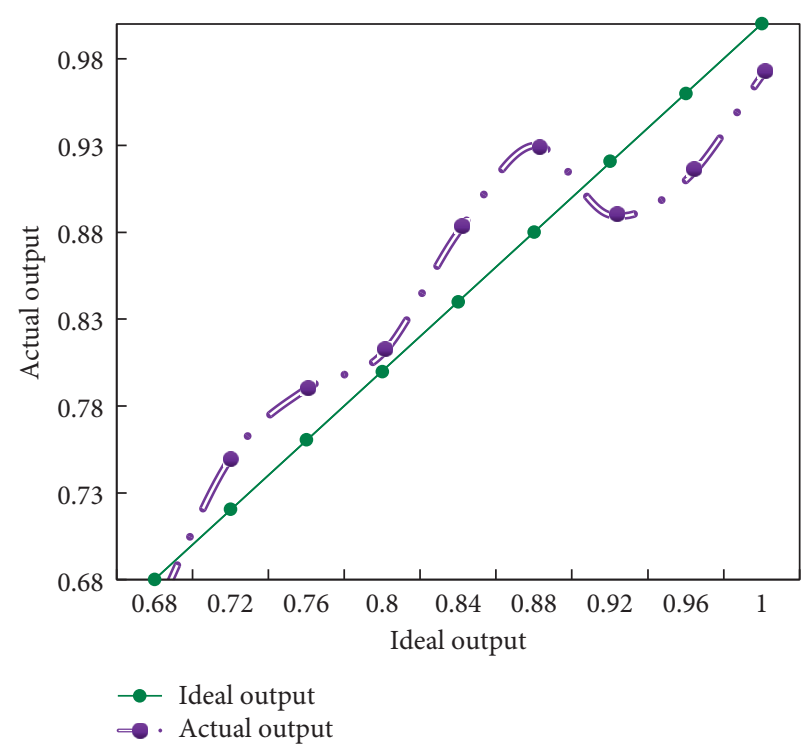

Figure 7: Network evaluation regression analysis.

interaction with the learning environment, they support themselves and the environment and gain the dual development of cognition and identity, which ultimately shows their love for learning. A love of learning is a necessary condition of DL.

Reasonable curriculum planning is not only conducive to cultivating students' comprehensive ability to use language knowledge, but it also allows them to use this tool to deepen their study of specialized courses in English teaching at medical universities. Medical schools should pay attention to the variety of medical English curricula, such as creating special practice subjects such as hospital situational conversation, translation, and writing skills. Most textbooks only include reading articles and vocabulary exercises in the writing mode, which violates the law of language learning and fails to pique learners' interest. As a result, high-level and systematic specialized English textbooks are required for medical English teaching. The network was used to evaluate 10 teachers who were chosen at random from nonsamples. The outcomes of the evaluation were compared to the actual outcomes of the evaluation. The correlation coefficient between them was 0 9027, and the evaluation results were very accurate, according to Figure 8 of the regression analysis.

Therefore, medical education should foster not only disciplinary literacy but also a humanistic spirit in medical students. We can only cultivate high-quality medical workers if both are given equal attention. This also reflects the importance of the medical English learning stage. As a result, the focus of English curriculum reform in medical schools should be on improving the infiltration of humanistic quality education. To run humanistic spirit through English teaching in medical colleges and universities, the key is to find the meeting point between English language and humanistic spirit cultivation. That is, to fully tap the part of college English textbooks that reflects the deepest 


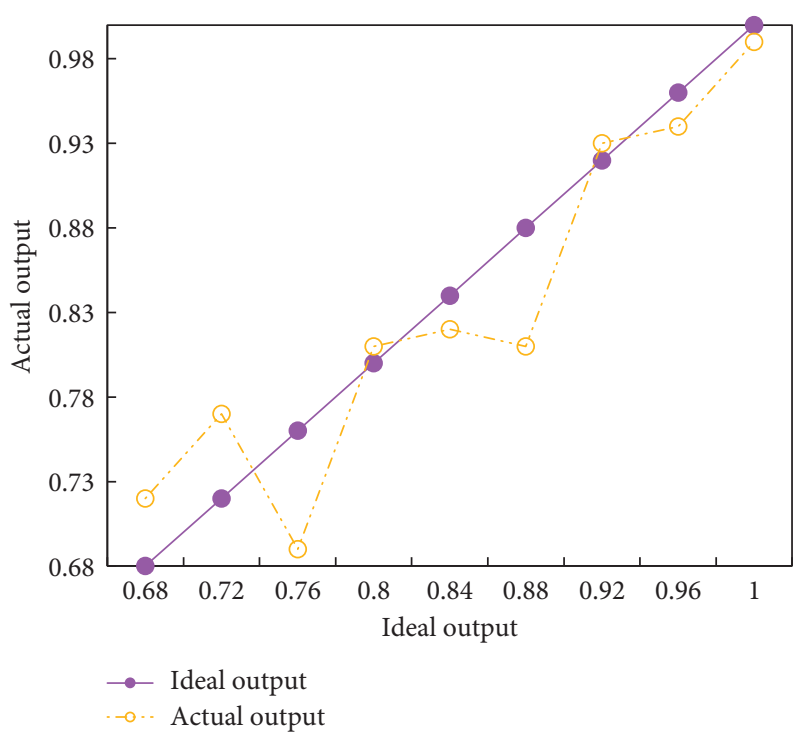

Figure 8: Regression analysis of evaluation results.

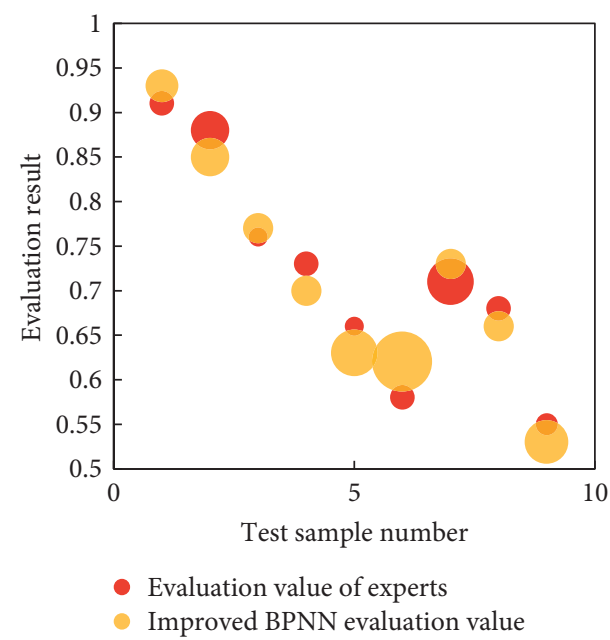

Figure 9: The expert evaluation results are compared with the improved BPNN evaluation results.

connotation of humanistic spirit and can stimulate students' thoughts and emotions, thereby combining the discipline of English teaching with humanistic spirit cultivation.

Formerly, the formative evaluation content commonly used by English teachers in domestic medical colleges only focused on the students' attendance, their enthusiasm for answering questions in class, and the scores of staged tests. The evaluation methods mostly adopted the single form of "teacher evaluation," and the evaluation standards were mostly controlled by the teachers themselves, lacking the supervision of authoritative departments, so the scientificity and fairness of the evaluation were difficult to guarantee (Figures 9 and 10).

English courses at all stages in medical colleges and universities are a compulsory basic course for college students. It is a kind of teaching system that is guided by English teaching theory, compiles courses and conducts teaching based on basic,

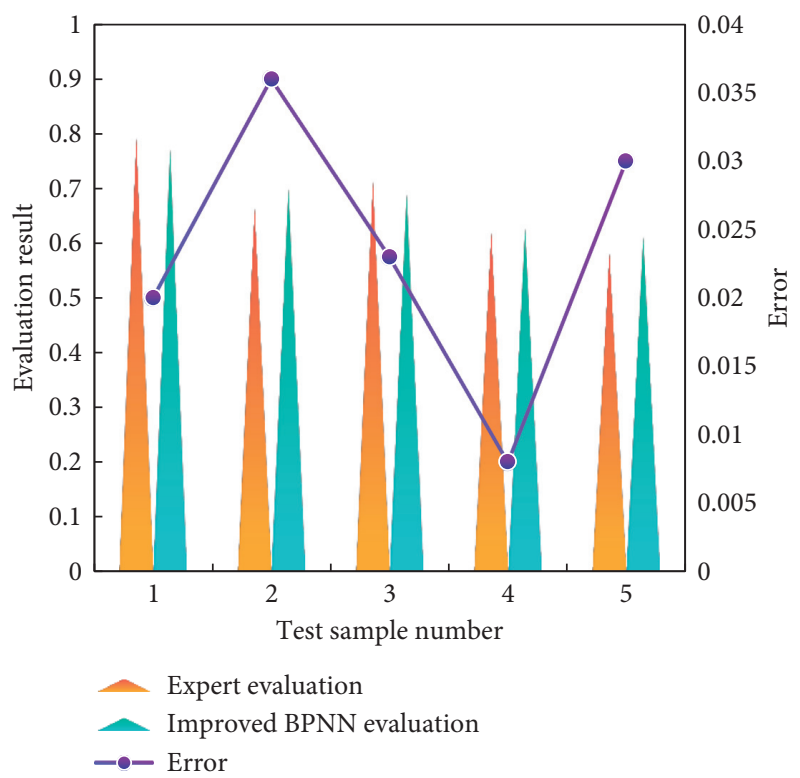

FIGURE 10: The simulation results are compared with the evaluation results given by experts.

humanistic, and professional principles, and integrates various teaching modes and teaching means (Figure 10).

Through the study of medical English, students can basically understand the professional courses taught in English and be able to write English abstracts of professional papers. Actively promote the combination of medical English in medical colleges and universities with the latest achievements in basic medical research and basic medicine, and finally, promote the continuous innovation of the overall education model in medical colleges and universities.

On the basis of improving the original teaching model, it is necessary for teachers who implement this new teaching system to actively innovate, change their thinking, and highlight the characteristics of English in medical colleges and universities. Classroom instruction that takes place face-toface is a genuine language exchange. Online learning will not be able to replace teachers' concise language expression or the language practice environment created by teachers and students. Teachers can provide timely informational feedback to students, help them develop a sense of learning identity, and boost their motivation and enthusiasm for learning. It has the ability to fully reflect on whether the new English teaching system is rational and scientific. In general, medical students' evaluations are divided into two types: formative and summative assessments are used, and students' regular grades are factored into the final grade calculation. To cultivate students' autonomy in learning, a spirit of unity and cooperation, and an open and innovative thinking mode, combine homework after class and a final "open + closed-book" exam organically.

\section{Conclusion}

DL is geared toward real-world problem solving, with a focus on learning reflection and self-cognition. The EMET model based on the improved BPNN algorithm fully exploits 
the benefits of DL, a new EMET method. It has the ability to objectively and fairly assess teachers' teaching quality, arouse teachers' enthusiasm for teaching, improve teaching quality, and cultivate exceptional talents. The error between the output identification value and the true value of the mathematical model established by using the improved BPNN has been shown to be very small in practice, allowing teachers' teaching quality and effects to be evaluated more scientifically and accurately, providing a useful reference value for EMET research.

The success of China's university EMET system, as proposed in this study, is based on a strong theoretical foundation. Teachers must pay close attention to their students' participation and input in the classroom. Furthermore, the theory of functional linguistics directs us to emphasize the importance of listening and speaking skills in basic English teaching and to quickly improve students' basic skills from a functional standpoint. It is hoped that this system will provide ideas and methods for English teaching reform in Chinese medical colleges and that the instrumental and humanistic nature of English in medical colleges will be realized.

\section{Data Availability}

The data used to support the findings of this study are included within the article.

\section{Conflicts of Interest}

The authors declare that they have no conflicts of interest.

\section{References}

[1] B. Anthony, A. Kamaludin, A. Romli et al., "Exploring the role of blended learning for teaching and learning effectiveness in institutions of higher learning: an empirical investigation," Education and Information Technologies, vol. 24, no. 6, pp. 3433-3466, 2019.

[2] A. Nathoo, G. Bekaroo, T. Gangabissoon, and A. Santokhee, "Using tangible user interfaces for teaching concepts of internet of things: usability and learning effectiveness," Interactive Technology and Smart Education, vol. 13, 2020.

[3] T. Yanmei and A. Jie, "Research on teaching quality evaluation system based on the mathematical model of teaching efficiency," International Journal for Engineering Modelling, vol. 31, no. 1, pp. 236-243, 2018.

[4] A. Abdelhadi and M. Nurunnabi, "Engineering student evaluation of teaching quality in Saudi Arabia," International Journal of Engineering Education, vol. 35, no. 1, pp. 262-272, 2019.

[5] F. Zhao and L. Chen, "Empirical study on the teaching quality evaluation system of college physics informatization based on fuzzy comprehensive evaluation method," Revista de la Facultad de Ingenieria, vol. 32, no. 14, pp. 58-66, 2017.

[6] Y. Wang and M. Zhang, "Teaching quality evaluation index of civil engineering training based on optimal regression method," Revista de la Facultad de Ingenieria, vol. 32, no. 10, pp. 654-660, 2017.

[7] W. Ma, "Design and implementation of teaching quality evaluation system based on web technology," Boletin Tecnico/ Technical Bulletin, vol. 55, no. 15, pp. 340-347, 2017.
[8] J. Zhao and L. Qin, "Evaluation index of physical education teaching quality based on index clustering method," Boletin Tecnico/Technical Bulletin, vol. 55, no. 12, pp. 734-739, 2017.

[9] X. Yang, "Research on the teaching quality evaluation of law course in colleges based on the AHP model," Revista de la Facultad de Ingenieria, vol. 32, no. 14, pp. 713-717, 2017.

[10] S. Zhiyong, P. Muthukrishnan, and G. Kaur, "College English language teaching reform and key factors determining EFL teachers' professional development," European Journal of Educational Research, vol. 9, no. 4, pp. 1393-1404, 2020.

[11] R.. Evaluation, "Model of multi-level teaching quality," Advances in Applied Mathematics, vol. 07, no. 8, pp. 1071-1084, 2018.

[12] J. Zuo and P. Jia, "Empirical research on evaluation system of college mathematics teaching quality based on bp neural network," Revista de la Facultad de Ingenieria, vol. 32, no. 14, pp. 188-193, 2017.

[13] J. Wang, C. Wang, and X. Sun, "Application of the improved bp network algorithm in the classroom teaching quality evaluation of the colleges and universities," Revista de la Facultad de Ingenieria, vol. 32, no. 14, pp. 225-230, 2017.

[14] Y. Wang, C. Sun, and Y. Guo, "A multi-attribute fuzzy evaluation model for the teaching quality of physical education in colleges and its implementation strategies," International Journal of Emerging Technologies in Learning (iJET), vol. 16, no. 2, p. 159, 2021.

[15] Y. Wu and Z. Pei, "An investigation of critical thinking manifested in the questions of EFL textbooks for tertiary-level English majors of China," American Journal of Education and Learning, vol. 3, no. 2, pp. 72-84, 2018.

[16] Y. Zeng, "Evaluation of physical education teaching quality in colleges based on the hybrid technology of data mining and hidden markov model," International Journal of Emerging Technologies in Learning (iJET), vol. 15, no. 1, p. 4, 2020.

[17] N. Peng, L. Wang, L. Liu, and Y. Qu, "A preliminary study on the validity of the paperless college English test based on the computer network platform-take the iTEST test system As an example," Journal of Physics: Conference Series, vol. 1648, no. 2, p. 022192, 2020 October.

[18] J. Singh and J. Singh, "A survey on machine learning-based malware detection in executable files," Journal of Systems Architecture, vol. 112, Article ID 101861, 2021.

[19] M. Zabihi and N. Babajani, "Modeling, optimization and experimental studies of supported nano-bimetallic catalyst for simultaneous total conversion of toluene and cyclohexane in air using a hybrid intelligent algorithm," RSC Advances, vol. 8, no. 31, pp. 17346-17356, 2018.

[20] Y. Guo, O. H. Ba, and Y. Jiang, "Evaluation index of practical teaching quality of medical information management based on stepwise regression method," Revista de la Facultad de Ingenieria, vol. 32, no. 10, pp. 555-563, 2017.

[21] S. Only, "An improved fuzzy comprehensive evaluation of public class teaching quality in college physical education based on grey system theory," Boletin Tecnico/technical Bulletin, vol. 55, no. 6, pp. 580-586, 2017.

[22] S. García, B. Olsen, and A. Simbaqueba, "Teaching quality in Colombia: analysing twenty years of awarding a national bestteacher prize," European Journal of Teacher Education, vol. 15, pp. 1-20, 2021.

[23] E. Hakoköngäs, O. Halmesvaara, and I. Sakki, "Persuasion through bitter humor: multimodal discourse analysis of rhetoric in internet memes of two far-right groups in Finland," Social Media+ Society, vol. 6, no. 2, Article ID 2056305120921575, 2020. 
[24] T. Tang, "Supply chain demand forecasting model based on ARIMA and BP neural network and its comparative analysis," Advances in Applied Mathematics, vol. 10, no. 6, pp. 20412049, 2021.

[25] S. Tang and F. Yu, "Construction and verification of retinal vessel segmentation algorithm for color fundus image under BP neural network model," The Journal of Supercomputing, vol. 77 , no. 1, pp. 1-15, 2021. 